\title{
Nephrology
}

\section{Diabetic Nephropathy: The Proteinuria Hypothesis}

\author{
Mark E. Williams \\ Joslin Diabetes Center, Harvard Medical School, Boston, Mass., USA
}

\section{Key Words}

Diabetic nephropathy · Proteinuria, clinical trials · Hypertension - Angiotensin - Converting enzyme inhibitors $\cdot$ Angiotensin receptor blockers

\begin{abstract}
Background/Aims: Proteinuria, nearly a universal finding in progressive kidney disease, has been the subject of frequent recent analyses in the renal literature. Proteinuria is a hallmark of diabetic nephropathy: microalbuminuria is the principal early predictor for progression of diabetic glomerulopathy, and proteinuria may be viewed as a measure of the severity and promoter of progression of nephropathy. Methods: This article critically reviews for the first time the full scope of diabetic proteinuria - complex molecular mechanisms, natural history, and analysis of treatment trials - in order to address the validity of 'the proteinuria hypothesis', i.e., that diabetic proteinuria is a modifiable determinant of renal progression. This hypothesis is analyzed in detail, including recent studies on the primary therapy of diabetic nephropathy, renin-angiotensin blockade. Results: As fully developed, this hypothesis consists of three postulates: that higher amounts of proteinuria predict progressive loss of function, that proteinuria reduction correlates with slowing progression, and that proteinuria is a surrogate endpoint for clinical trials. The latter postulate has not before been adequately linked to growing information about the first two postulates as they apply to
\end{abstract}

diabetic kidney disease. Conclusion: While diabetic nephropathy is a disease model for the potential use of proteinuria as a surrogate marker for renal progression, this shift in perspective will require prospective data from additional clinical trials, particularly of non-reninangiotensin blocking drugs, to be complete.

Copyright (C) 2005 S. Karger AG, Basel

\section{Introduction}

Diabetic kidney disease is characterized by excessive urinary albumin excretion followed by loss of kidney function. Proteinuria is a hallmark of diabetic nephropathy. The number of Americans diagnosed with diabetes mellitus has increased $61 \%$ over the last decade and will more than double by 2010. Data from five consecutive cross-sectional US national surveys, most recently NHANES 1999-2000, indicate that the most dramatic increase in diabetic cases has been in the most obese individuals [1], where the prevalence in 2000 was 3 times the level in 1960. Amidst an epidemic of diabetes, the disease has become the most common single cause of chronic kidney disease in the US and Europe [2, 3]. The incidence of diabetic nephropathy has more than doubled in the past decade [4], due largely to increasing prevalence of type 2 diabetes [4]. Microalbuminuria was present in $32.8 \%$ of adults with previously diagnosed diabetes in NHANES III (1988-1994) and in $27.5 \%$ of adults in NHANES 1999-2000 [5]. Diabetic nephropa-

\section{KARGER \\ Fax +4161306 1234 E-Mail karger@karger.ch} www.karger.com
(C) 2005 S. Karger AG, Basel 0250-8095/05/0252-0077\$22.00/0

Accessible online at: www.karger.com/ajn
Mark E. Williams, MD, FACP

1 Joslin Place

Boston, MA 02215 (USA)

Tel. +1 617732 2477, Fax +1 6177322467

E-Mail mark.williams@joslin.harvard.edu 


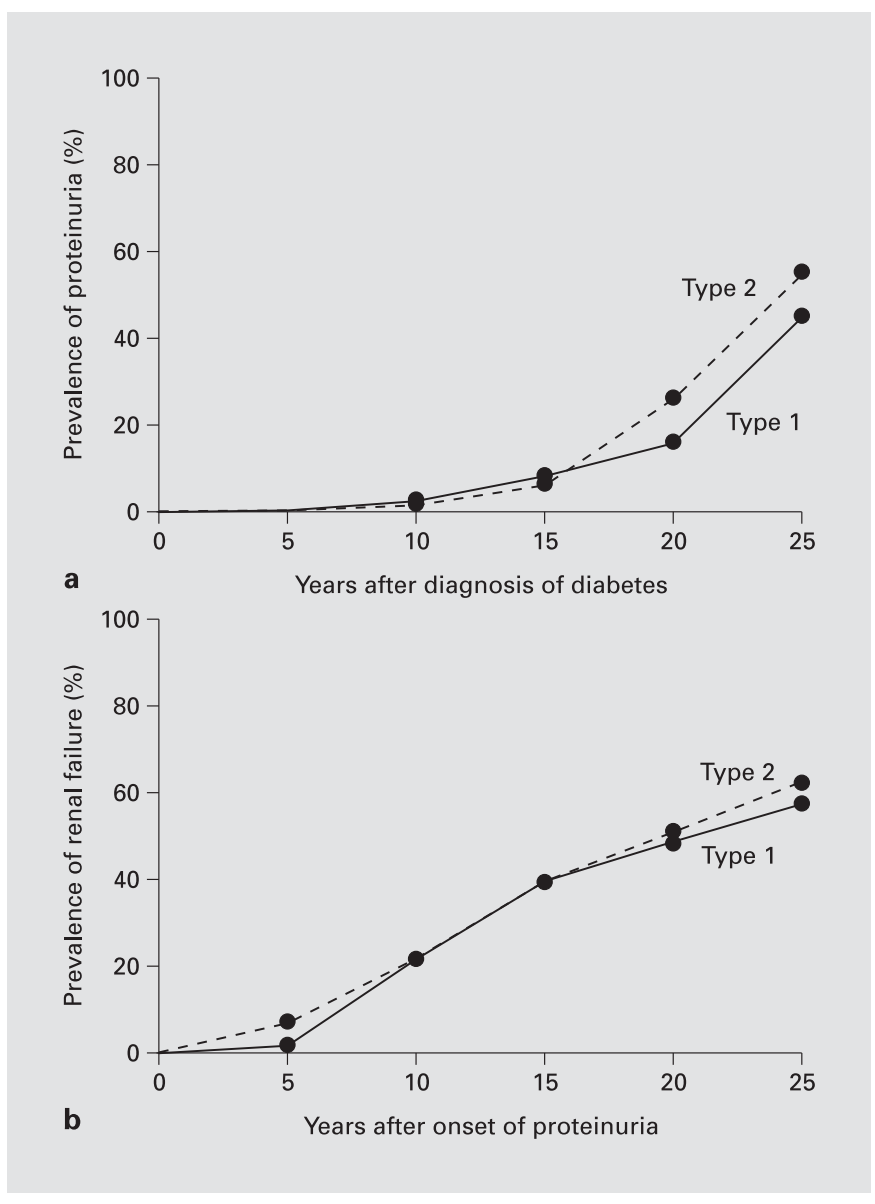

Fig. 1. Proteinuria (a) and progression to ESRD (b) in diabetic nephropathy in type 1 and type 2 diabetic patients. Similar rates of proteinuria and time of progression from onset of proteinuria to kidney failure occur in both types of diabetes [10].

thy now accounts for about $40 \%$ of new cases of endstage renal disease (ESRD) [6]. A recent study has estimated the annual health care costs of diabetic nephropathy in the US at USD 1.9 billion for type 1 and USD 15.0 billion for type 2 diabetes [7]. Nearly a universal finding in progressive kidney disease [8], proteinuria, predominantly albuminuria, has long been accepted as the clinical hallmark of diabetic nephropathy [9], and its most common laboratory manifestation (fig. 1) [10]. In NHANES II, $1 \%$ of the general adult population and $6.1 \%$ of diabetics screened demonstrated macroalbuminuria [11].

This article reports on the complexity of diabetic proteinuria and of its primary therapy, renin-angiotensin blockade. It analyzes the current importance given to di- abetic nephropathy in support of the "proteinuria hypothesis', i.e., that diabetic proteinuria is a modifiable determinant of renal progression. The concept that reducing proteinuria is an effective way to halt progression of the disease [12] is evaluated in detail.

Overt diabetic nephropathy is characterized by persistent proteinuria $(>0.5 \mathrm{~g} / 24 \mathrm{~h})$ or macroalbuminuria $(>300 \mathrm{mg} / 24 \mathrm{~h})$ [13]. In the natural history of the disease [14], proteinuria is preceded by stages of excessive glomerular filtration and of microalbuminuria, which signals an increased risk of progression to overt nephropathy. A progressive increase in proteinuria subsequently leads to a variable decline in renal function. While initial microalbuminuria may enter into remission [15], and fewer than half of microalbuminuric patients progress to higher levels of proteinuria [16], it remains the principal early predictor for progression at this time.

It is now widely accepted that proteinuria reduction is an appropriate therapeutic goal in chronic kidney disease with proteinuria [17]. Experimental and clinical studies continue to examine the role of proteinuria in diabetic nephropathy. Proteinuria signifies evidence of glomerular damage, and may be viewed as a measure of the severity of diabetic glomerulopathy. Heavy proteinuria in diabetic nephropathy is strongly associated with pathological changes of diffuse and, less commonly, the nodular form of diabetic glomerulosclerosis [18]. Early clinical reports noted nephrotic syndrome in $87 \%$ of type 1 and $70 \%$ of type 2 diabetic patients with nephropathy, and end-stage renal failure occurs in up to $75 \%$ of diabetic patients within 15 years of developing overt proteinuria [19]. The overall 10-year incidence of gross proteinuria in diabetic patients is about $33 \%$, with a prevalence similar in type 1 and type 2 patients [14]. Rising urinary protein excretion confers increased risk of overall mortality and fatal cardiovascular events in patients with diabetes mellitus. Four decades after the diagnosis of diabetes, almost $3 / 4$ of those lacking proteinuria are alive, in contrast to $1 / 10$ of those with proteinuria [20].

Factors which cause progression of kidney disease continue to be actively investigated, and include glomerular hypertension and hypertrophy, activation of coagulation pathways, and lipid deposition. Proteinuria is commonly viewed as a nonhemodynamic promoter of disease progression in diabetic nephropathy $[21,22]$. Treatment to delay progression of chronic renal failure now includes strict control of proteinuria [23] as the basis of therapy. Reducing proteinuria to less than $1 \mathrm{~g} / 24 \mathrm{~h}$ has been added to the targets of glycemic control and lowered blood pressure goals in preventing progression. Two decades of 
progress in retarding the progression of renal disease were recently reviewed [24].

More recent attention has focused on the prevalent 'proteinuria hypothesis', i.e. that proteinuria is a target of new therapies for tertiary prevention in diabetic nephropathy $[25,26]$. The proteinuria hypothesis consists of three postulates: (1) higher levels of proteinuria predict adverse clinical outcomes, (2) reduction in proteinuria correlates with slowing of renal progression, and (3) proteinuria is a surrogate endpoint and target of clinical trial interventions, in this case, for diabetic nephropathy. According to this hypothesis, measurement of proteinuria is correctly used to establish not only the diagnosis of overt diabetic nephropathy, but its risk of subsequent loss of renal function.

There is evidence to support the notion that the rate of progression of diabetic nephropathy may be best slowed or even reversed in its earlier stages [27]. However, clinical interventional trials for regulatory drug approval have historically targeted doubling of serum creatinine levels or patient mortality rates as primary outcome measures. Both measures are more likely to occur in later stages of diabetic nephropathy. Reducing proteinuria has emerged, then, as a potential outcome measure suitable for intervention in earlier stages of the disease. Proteinuria has been proposed as a surrogate which would allow shorter interventional trials involving nephroprotective therapy for diabetic nephropathy.

\section{Mechanism}

Understanding of the molecular mechanisms and ultrastructural changes causing proteinuria has made remarkable advances over the past few years [28], adding understanding to the previous concepts of glomerular barrier function [29]. While a full discussion of the mechanisms of the stage of microalbuminuria is beyond the scope of this review, it should be noted that the appearance of microalbuminuria is currently thought to be a consequence of generalized endothelial injury in the vasculature. Pathogenetic mechanisms involving the vasculature are likely to occur in glomerular endothelial cells and podocytes as well [30]. Several proposed mechanisms were reviewed by Garg and Bakris [31] to explain local (renal) and systemic vascular injury in diabetic patients with macroalbuminuria. MA is a powerful independent risk factor of cardiovascular disease in diabetes mellitus. Local injury to vascular smooth muscle cells and endothelial cells may increase vascular permeability in the kid- neys and systemically. While systemic hypertension is the most important single determinant of MA in the diabetic, this relationship is more pronounced in patients with elevated C-reactive protein levels [32]. MA is a strong predictor of total and cardiovascular mortality in both type 1 and type 2 diabetes [31].

Determining the mechanisms of proteinuria specific to diabetes has importance for each postulate of the proteinuria hypothesis. Of four mechanisms cited for excessive protein excretion in general - increased glomerular filtration, inadequate tubular absorption, overflow, and increased tubular secretion - the dominant mechanism is glomerular. Proteinuria primarily reflects glomerular injury and increased glomerular permeability to macromolecules. The exact molecular mechanisms causing the breakdown of the glomerular filtration barrier in diabetes remain to be fully defined. It is widely accepted that the passage of proteins across the filtration barrier can be affected by several factors, including the hemodynamic pressure gradient across the glomerular basement membrane and factors intrinsic to the filtration barrier, including the pore size and extent of anion charges [29]. While mechanisms altering the protein-selective properties of the diabetic glomerular capillary wall are not fully understood, evidence exists for hemodynamic as well as intrinsic basement membrane changes as causes of diabetic proteinuria (fig. 2) [33]. Angiotensin exerts complex hemodynamic and nonhemodynamic actions that may contribute to diabetic nephropathy, including induction of systemic vasoconstriction, increased glomerular arteriolar resistance, increase in glomerular capillary pressure, increased glomerular capillary permeability, reduction in the filtration surface area, stimulation of extracellular matrix proteins, and stimulation of renal proliferation and fibrogenic chemokines (table 1) [34-36]. The structural basis for the leak may reside within the glomerular basement membrane as well as in the nearby epithelial cell layer; specific mechanisms may include basement membrane damage due to lucent deposits, and focal foot process degeneration of the podocytes.

Several pathological changes are characteristic of diabetic glomerulosclerosis (fig. 3a), including nodular and/ or diffuse sclerosis of glomeruli, increased basement membrane thickening, increased mesangial matrix, hyaline arteriolopathy of afferent and efferent vasculature, and varying degrees of interstitial fibrosis with tubular atrophy [4, 37]. Some renal structural abnormalities are known to precede the development of proteinuria in diabetic nephropathy, including increased basement membrane width and mesangial expansion [38]. The degree of 
Fig. 2. Mechanisms of proteinuria in diabetic nephropathy. GBM = Glomerular basement membrane.

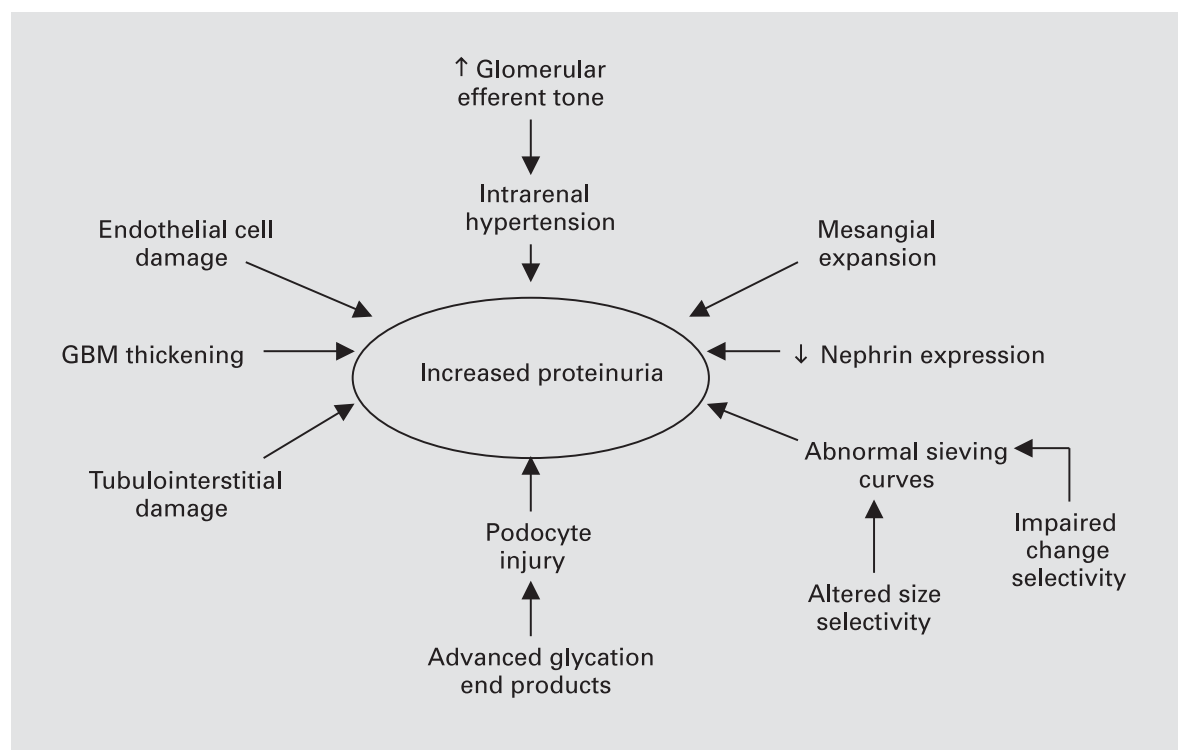

Table 1. Role of angiotensin II in diabetic nephropathy

\author{
Systemic vasoconstriction \\ Increased glomerular arteriolar resistance \\ Increased glomerular capillary pressure \\ Increased glomerular capillary permeability \\ Reduced filtration surface area \\ Stimulation of extracellular matrix \\ Stimulation of cell growth and proliferation
}

both mesangial and interstitial expansion has been found to correlate with the degree of albuminuria. Progressive mesangial expansion may be due to glycoproteins, collagen, or other factors [39]. Electron-dense deposits in or around the glomerular basement membrane may restrict the glomerular capillary filtration surface area and lead to proteinuria.

Glomerular permselectivity (fig. 3b) involves two adjacent molecular filters: the glomerular basement membrane and the slit diaphragm [40]. The glomerular basement membrane in humans (fig. 3c) is a complex threelayered structure comprised of endothelial cells with fenestrations, the dense fibrillar glomerular basement membrane itself, and podocytes, the outer visceral epithelial cells. (Previously viewed as an insignificant part of the barrier, recent data suggest that the endothelium may play a role in glomerular permselectivity [41]. The endothelial barrier properties may derive from its cell coat, or glycocalyx.) Between the interdigitating foot processes of the podocytes arises the slit diaphragm, a zipper-like com- plex. In humans the basement membrane layer, attached to endothelial and visceral epithelial cells, has a thickness of 250-350 nm. The most abundant single component of the filtration membrane is type IV collagen.

The progression from normal albumin excretion to overt diabetic proteinuria correlates with the loss of size and charge selectivity of the filtration barrier [18]. Dysfunction of the size selectivity properties of the intrinsic glomerular barrier to plasma protein filtration has been evaluated in both type 1 and type 2 diabetes. Fractional clearances of albumin, $\mathrm{IgG}$, and neutral dextrans suggest a distribution of glomerular basement membrane pore radius toward larger pore sizes [18, 42]. Concomitant changes in charge selectivity as well may contribute to albuminuria in type 2 diabetes. In other experimental models of diabetic nephropathy, proteinuria is associated with a reduction in slit pore density.

Renal hemodynamics play a critical role in renal hyperfiltration of early diabetes, where glomerular filtration rates are supranormal [43]. A dominant theory based on animal models of diabetic nephropathy has been that glomerular hypertension secondary to reduced intrarenal vascular resistance leads to glomerular structural damage, including endothelial and epithelial cell damage, and disruption of the filtration barrier [44]. More recent investigation has focused on the roles of podocyte injury and nephrin in diabetic nephropathy. One of the most prominent ultrastructural abnormalities is podocyte loss [45]. Injury and loss of podocytes is a prominent ultrastructural abnormality in diabetic nephropathy [46, 47]. Vis- 

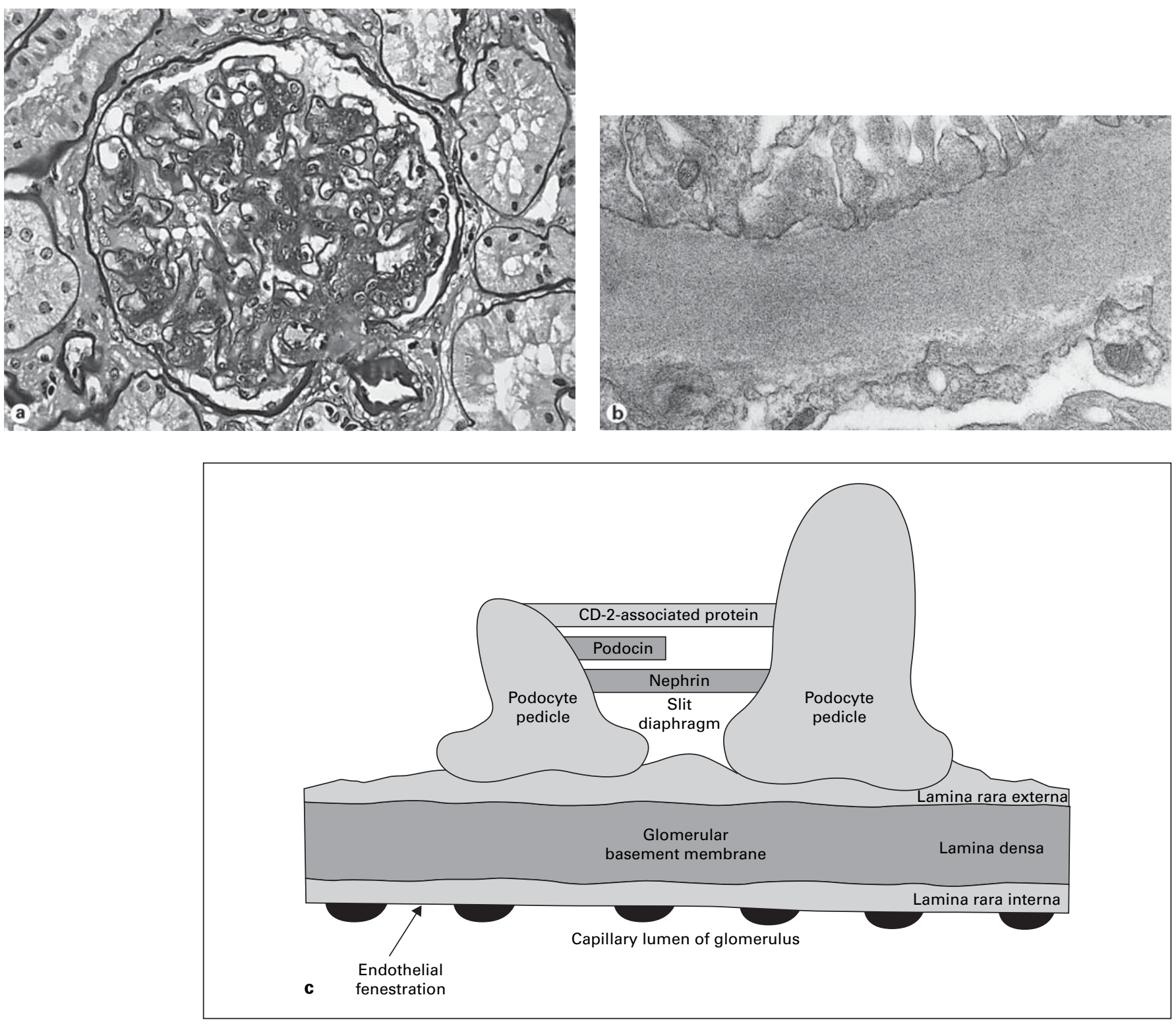

Fig. 3. a Pathological changes of advanced diabetic nephropathy include increased glomerular basement membrane thickness, mesangial matrix expansion, nodular glomerulosclerosis, glomerular hypertrophy, and arteriolopathy of afferent and efferent arterioles. b Electron microscopy showing increased basement membrane thickness. c The barrier to proteinuria. Schematic drawing of the visual glomerular epithelial cells (podocytes) lining the outer aspect of the glomerular basement membrane. Foot processes are connected by the slit diaphragm with nephrin, podocin, and other proteins. Proposed mechanisms of diabetic proteinuria include structural changes to the basement membrane, hemodynamic injury to podocytes, decreased number of podocytes, damaged slit diaphragm components, and reduced expression of nephrin.

ceral epithelial cell injury and reduction in the number of podocytes per glomerulus leave fewer podocytes to cover the surface area [48]. Increased synthesis of collagen by podocytes could lead to glomerular basement membrane thickening, or excessive amounts of secreted vascular en- dothelial growth factor could enhance permeability of the barrier to macromolecules. Several mechanisms of podocyte loss have been speculated. Mutations in podocyte genes have also been implicated in susceptibility to glomerular disease. A recent study reported that loss of 
CD-2-associated protein, a component of the glomerular filtration complex, may modulate disease not only because of its structural role in the slit diaphragm, but because it also directs proteins to the podocyte degradative pathway [49].

Nephrin is a 1,241-residue transmembrane cytoskeleton protein gene product localized to the filtration slit area between foot processes of the podocytes, and is essential for the formation of the zipper-like slit diaphragm structure [50]. Adler [51] emphasized the complexity of diabetic proteinuria in a recent Nephrology Forum review of podocyte pathology and nephrin in diabetic nephropathy. The author argued that podocyte injury in diabetic proteinuria may be mediated by signal transduction changes, cytoskeletal injury, alterations in the podocyte slit pore membrane, detachment from the glomerular basement membrane, and apoptosis. Adequate experimental data support the above mechanisms of podocyte injury. However, changes in the slit diaphragm related to nephrin expression, also reviewed by Adler, have been far more extensively explored. Nephrin expression is regulated in a complex way [50], and reduced gene production or dislocation of nephrin has been implicated in nondiabetic models of proteinuria kidney disease $[52,53]$. A reduction in nephrin expression may be a determinant of glomerular protein leakage in experimental diabetic nephropathy [54-56]. Ultrastructural and immunohistochemical studies have shown that nephrin is diminished in the glomeruli of diabetic rats $[51,55,57]$. In the diabetic rat model, reduction in glomerular nephrin gene expression determined by quantitative real-time PCR is temporally associated with increasing albuminuria [55, 58]. Some human data also suggest a downregulation of nephrin expression in the diabetic kidney, in both type 1 and type 2 diabetic nephropathy, perhaps mediated by angiotensin II and glycated albumin [59]. A recent study by Langham et al. [60] reported a $62 \%$ reduction in nephrin expression in glomeruli from patients with diabetic nephropathy. Expression of nephrin mRNA was reduced and inversely related to the severity of proteinuria in another recent small study of type 2 patients with nephropathy [61]. A gene expression profiling study using oligonucleotide microarray analyses reported the nephrin gene to be among those downregulated in diabetic nephropathy [62]. Reduced nephrin mRNA and protein expression may be associated with podocyte ultrastructural abnormalities, providing one potential mechanism for proteinuria in diabetic nephropathy $[63,64]$. A potentially important interaction linking angiotensin II and nephrin was also reviewed in the analysis by Adler [51]. Nephrin expression decreases acutely when podocytes in culture are incubated with angiotensin II, suggesting a direct influence of angiotensin on nephrin. Recent experimental data have shown that renin-angiotensin system (RAS) blockade results in a change in nephrin expression in diabetes [54, 58]. Furthermore, nephrin mRNA expression, reduced in diabetes, can be preserved by angiotensin-converting enzyme inhibitor (ACEI) [60]. The signaling pathway between angiotensin and nephrin expression is not clear. These reports suggest that the RAS affects proteinuria in diabetic nephropathy in part by effects on nephrin, and that ACE inhibition might modulate proteinuria in diabetic nephropathy by ameliorating diabetes-induced changes in nephrin synthesis.

The K/DOQI Work Group has recommended that urinary albumin excretion is the appropriate measure for monitoring chronic kidney disease [65] and that albumin and total protein excretion are correlated. Recently it has been proposed that the concept of increased albumin permeability as the sole abnormality causing proteinuria, with no defect in tubular retrieval of albumin, is inadequate [66]. Albumin and other plasma proteins filtered through the glomerulus undergo tubular absorption and degradation. As a result, albuminuria may be importantly influenced by tubular albumin metabolism. The fragmentation of filtered albumin is extensive, so that albumin in the urine may exist in conventional immunoreactive as well as conventionally unmeasured, immunounreactive forms [67]. A recent study proposed that in twenty diabetic patients with macroalbuminuria, large quantities of protein fragments not routinely measured clinically were present [68]. The role of defects in albumin retrieval in progression of diabetic nephropathy deserves further exploration.

It has long been understood that, as loss of kidney function progresses in diabetes, tubulointerstitial dysfunction in the form of low-molecular-weight tubular proteinuria may also become evident [69]. Diabetic nephropathy is now understood to be a disease which affects the entire nephron, i.e. the tubulointerstitium as well as the glomerulus [70]. Severity of proteinuria has been correlated with the extent of tubulointerstitial injury in experimental nondiabetic renal disease $[71,72]$. Tubulointerstitial injury has been the focus of increasing investigation in relation to glomerular injury and as an important pathological predictor of kidney impairment in diabetes [73]. Pathology of the interstitium in diabetic nephropathy includes tubular basement membrane thickening, tubular fibrosis and atrophy, and arteriolosclerosis. Interstitial expansion correlates with the extent of albuminuria, and 
Fig. 4. Natural history of diabetic nephropathy, including changes in glomerular filtration and proteinuria over time. Proteinuria reduction is shown as a tertiary prevention. GFR = Glomerular filtration rate.

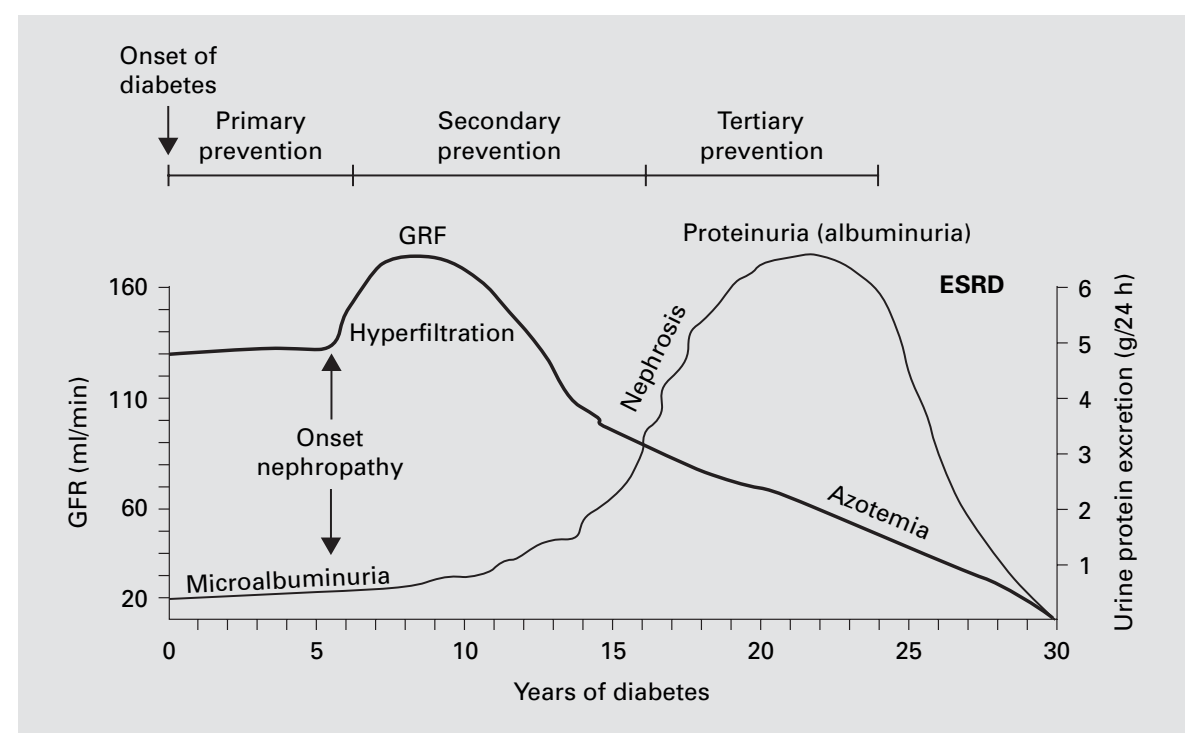

interstitial fibrosis correlates more closely with loss of function than does glomerular injury [70].

Not specific to diabetes, a more recently developed corollary of relevance to the proteinuria hypothesis is that increased protein filtration and excretion may contribute to the pathogenesis of glomerular lesions and disease progression in nephropathy $[74,75]$. The proposed effects of proteinuria on the kidney include increased severity of glomerulosclerosis as well as tubulointerstitial injury, in both experimental models of proteinuric kidney disease and in humans. The degree of glomerular proteinuria is known to correlate with histologic interstitial fibrosis [76]. Filtered and reabsorbed proteins cause release of vasoactive and inflammatory substances into the interstitium of the kidney, resulting in fibroblast proliferation and interstitial inflammation. Mechanisms which have been proposed for the dangers of proteinuria include direct mesangial toxicity, toxicity of specific filtered proteins, and induction of proinflammatory molecules [77, 78]. More recent data also suggest that proteinuria is responsible for tubular cell injury as well as interstitial damage, due to tubular overload of proteins, exceeding the lysosomal capacity for endocytosis [79]. The complex reaction includes lysosomal rupture and release of endothelial and mononuclear cell chemotactic proteins. Excessive filtered protein reaching the proximal tubule may lead to peritubular inflammation and fibrosis. Recently reported mechanisms of tubulointerstitial injury involving the proximal tubule attributed to proteinuria include regulation of proximal tubular gene expression profiling [80] and modulation of chemokine production $[81,82]$ by proteinuria. These complex and multifactorial mechanisms linking proteinuria and tubulointersitial injury give further support to the first postulate of the proteinuria hypothesis.

\section{Natural History}

Clinical proteinuria was first noted in patients with diabetes over a century ago, and was described in association with diabetic glomerulosclerosis in a pathological report by Kimmelstiel and Wilson [83] in 1936. The sequence of proteinuria followed by loss of renal function was not described until 40 years later. Only a decade later was another distinct stage of nephropathy, microalbuminuria, identified, in type 1 diabetes. These features of the natural history of diabetic nephropathy are now widely known (fig. 4).

Diabetic nephropathy is clinically defined by the presence of persistent proteinuria greater than $0.5 \mathrm{~g} /$ day. The albumin excretion rate in patients with clinical proteinuria is generally $>200-300 \mu \mathrm{g} / \mathrm{min}$ [84]. The average time to proteinuria from the time of diagnosis of type 1 diabetes is 19 years. Proteinuria tends to increase over time in untreated patients, and the majority of such patients become nephrotic. The yearly increase in protein excretion averages about $20 \%$, but wide variation occurs in both incipient (microalbuminuria) and overt nephropathy [85]. Over a 2-year period in one study, average urine 
protein excretion increased from 1.8 to $3.3 \mathrm{~g} /$ day $[86,87]$. The amount of total proteinuria in diabetic nephropathy patients is typically subnephrotic $(<3.5 \mathrm{~g} / 24 \mathrm{~h})$ or nephrotic, with as many as $70-80 \%$ being nephrotic in some earlier studies of type 1 and type 2 patients with nephropathy [88]. Hypertension is an early feature in the course of persistent proteinuria, even when renal function is normal or only slightly impaired $[89,90]$. Diabetic patients with persistent proteinuria have a high risk of developing proliferative retinopathy.

Without intervention, renal function falls over a period of several years once overt nephropathy is present, but at a highly variable rate. In many cases, diabetic patients with heavy proteinuria have the worst renal prognosis. Proteinuria may decline as glomerular filtration falls and renal failure becomes advanced. In type $1 \mathrm{pa}-$ tients with clinical proteinuria, glomerular function declines by about $12 \mathrm{ml} / \mathrm{min} /$ year. ESRD develops in 50\% of patients over 10 years and in $75 \%$ over 20 years. In type 1 patients, on average, the natural history of diabetic nephropathy leads to death 6 years after the start of persistent proteinuria, although the range appears to be very wide. The overall sequence is similar in type 2 patients, but uncertainties may exist because of inaccurate dating of the onset of diabetes and a higher rate of nondiabetic or atypical features of diabetic glomerulosclerosis. The decline is more variable in type 2 patients [6] and the progression rate to ESRD may be as low as $20 \%$ over 20 years. However, the progression of renal failure, while constant in individual patients, varies widely among patients. Improvements in the management of nephropathy have extended the time course from persistent proteinuria to renal failure in comparison to these historical estimates.

Albumin, a small- to medium-sized molecule, is the protein that has been most extensively studied. As noted by Mogensen and Christensen [86] in 1984, the albumin excretion rate that corresponds to clinical proteinuria is generally greater than $200-300 \mu \mathrm{g} / \mathrm{min}$. In patients with microalbuminuria, yearly increases in the albumin excretion rate of about $25 \mu \mathrm{g} / \mathrm{min}$ have been shown [90], although the range is wide [89]. Wide standard deviations are seen in the yearly increase in albumin excretion rate, but the vast majority of patients, particularly in type 1 diabetes, progress to clinical proteinuria over a few years. In its most advanced stages, diabetic glomerular proteinuria becomes less selective [91], with a significant leak of large proteins including both albumin and $\mathrm{IgG}$, and tubular proteinuria leads to larger losses of markers such as $\beta_{2}$-microglobulin $[18,69,92]$. While diabetic patients with heavy proteinuria exhibit an abnormal enhancement of very high molecular weight dextran clearance, the changes are small compared to a 1,000-fold increase or more in albumin excretion [84]. Newer parameters suggested to monitor the progression of diabetic nephropathy include the measurement of immunoglobulin subclasses, such as IgG4, which may be differentially eliminated due to charge as well as to nonenzymatic glycation [93].

\section{Proteinuria Predicts}

The first postulate of the proteinuria hypothesis is that proteinuria is an independent predictor of ESRD, so that the level of measured protein losses is an explanatory variable for the severity of glomerular damage. The postulate accepts the existence of other independent prognostic factors of renal progression, such as hypertension, genetics, or dietary intake.

More than 20 years ago, Hostetter et al. [94] proposed that proteinuria by itself could exacerbate glomerulosclerosis. A variety of experimental models and human kidney diseases have now indicated that baseline proteinuria should be accepted as an independent and modifiable risk factor for renal disease [95], at least certain levels of proteinuria in certain conditions. More severe proteinuria is correlated with a faster rate of progression to renal failure $[72,96,97]$. In the Modification of Diet in Renal Disease (MDRD) study (which excluded diabetic nephropathy patients), for example, baseline proteinuria was one of six factors and a continuous variable which independently predicted faster glomerular filtration rate decline [98]. Other studies have linked proteinuria to ESRD and renal death [97].

The effects of proteinuria on the kidney may be detrimental well under nephrotic levels of protein excretion; the adverse association of proteinuria with loss of function is stronger in patients with over $1 \mathrm{~g}$ of total protein excretion per $24 \mathrm{~h}[95,99]$. However, it should be recognized that a main limitation of proteinuria as a marker of chronic kidney disease is that the inherent intraindividual variation in urinary protein excretion is even greater than that for serum creatinine alone [100]. Similar to the rate of decline of renal function itself, excretion of total protein or albumin in the urine varies within an individual [87], up to a standard deviation of as much as $40-50 \%$. It also appears that many exceptions occur to the link between proteinuria and poor outcomes [30, $101]$. 
Fig. 5. Effect of baseline albuminuria on renal endpoint (combined endpoint of doubling of serum creatinine, ESRD, or death) and on the individual component of ESRD in the RENAAL study. Adjusted for baseline risk markers, the renal endpoint was 5-fold higher and risk of progression for ESRD 8-fold higher in the high versus the low albuminuria group [see 101].
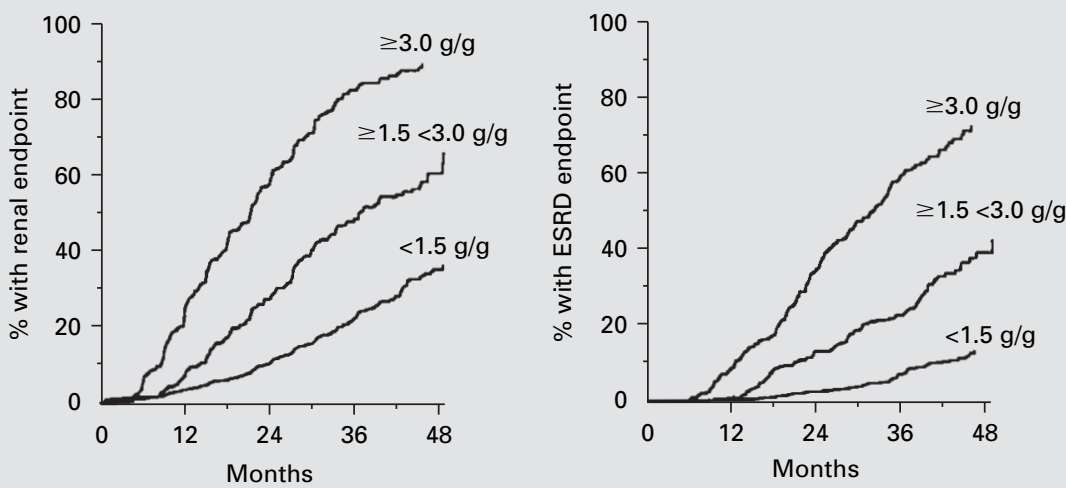

Evaluated in a diverse number of glomerular diseases, proteinuria has become a key clinical issue as a predictor of renal progression in human diabetic nephropathy, either at baseline levels or as a response to clinical intervention. Almost 40 years ago, Gellman et al. [102] reported a relationship between renal biopsy results of glomerulosclerosis and clinical proteinuria in type 1 diabetes. In 1972, Watkins et al. [9] reported that, while daily 24-hour proteinuria in diabetic nephropathy showed considerable variation, nephrotic proteinuria was associated with advanced histologic changes, and that the chief difference between those who survived and those who did not was heavy proteinuria [14]. In the landmark Collaborative Study Group trial of type 1 diabetic nephropathy, heavy proteinuria doubled the risk of nephropathy progression [22]. Patients who reached serum creatinine doubling endpoints had baseline total protein excretion of $4.99 \mathrm{~g} /$ day compare to $2.34 \mathrm{~g}$ in those who did not reach creatinine doubling. In the phase II clinical trial of the AGE inhibitor pimagedine in a similar population, subset analysis showed that those with the largest protein excretion were again at greatest risk for doubling of creatinine [103].

A decade ago, a study of 121 hypertensive type 2 diabetic patients with nephropathy revealed that loss of renal function was greater in patients with overt nephropathy at baseline (urine albumin excretion $>300 \mathrm{mg} / 24 \mathrm{~h}$ ) compared with patients enrolled with lower amounts of proteinuria [104]. Of two recent well-known studies on the use of angiotensin receptor blockers (ARBs) in patients with nephropathy due to type 2 diabetes, the Irbesartan Diabetic Nephropathy Trial (IDNT) [105] and the Reduction of Endpoints in NIDDM with the Angiotensin II Antagonist Losartan (RENAAL) trial [106], proteinuria was a prospective outcome measure only in the latter. In the IDNT, baseline proteinuria averaged $2.9 \mathrm{~g} / 24 \mathrm{~h}$ in the irbesartan, amlodipine, and placebo groups. No data were reported on the relation of baseline proteinuria to renal outcome measures [105]. Unpublished data revealing a $14 \times$ increase in risk of progression to advanced disease when baseline proteinuria equaled $3-4 \mathrm{~g} / 24 \mathrm{~h}$ versus those with $1-2 \mathrm{~g} / 24 \mathrm{~h}$ were included in a recent review by Weir [107] on diabetes and hypertension. In the RENAAL study, proteinuria was a secondary endpoint. Median urinary albumin/creatinine ratios were 1,237 in the losartan group and 1,261 in the placebo group. Urinary albumin excretion tended to correlate with stage of hypertension at baseline [108]. While no relationship of baseline proteinuria to renal outcomes was included in the original report, subsequent analysis reported proteinuria to be the most important predictor of ESRD [109]. A recent target presented further outcome analysis of the secondary endpoint of albuminuria from the RENAAL study [110] including the effect of the amount of albuminuria at baseline. Baseline albuminuria was directly related to renal outcomes, and was a stronger predictor than other well-known risk parameters such as serum creatinine, blood pressure, $\mathrm{HbA1C}$, age, and ethnicity. The mean baseline albumin was $1.8 \mathrm{~g} / \mathrm{g}$ of urine creatinine. When baseline albuminuria was divided into high (73.0 $\mathrm{g} / \mathrm{g})$, intermediate $(71.5<3.0 \mathrm{~g} / \mathrm{g})$ and low $(<1.5 \mathrm{~g} / \mathrm{g})$ subgroups, the renal endpoint was 5 times higher for the high versus the low subgroup (fig. 5) even when adjusted for baseline risk markers. Data on total protein excretion were not presented. This large clinical trial has provided the firmest data available on the importance of large quantities of albumin to renal progression in diabetic nephropathy. 
Table 2. Strategies to reduce proteinuria

Blood pressure control to target levels

ACEI therapy

ARB therapy

Combination ACEI/ARB therapy

Low protein intake

Low sodium intake

Smoking cessation

Aldosterone antagonist therapy

\section{Reducing Proteinuria}

According to the second postulate, reducing proteinuria slows renal progression. While there is limited proof of concept from clinical interventional trials that specific titration against the level of proteinuria improves the efficacy of renoprotective therapy in most patients, many consider the ultimate goal of proteinuria remission $(<1 \mathrm{~g} /$ day) to be valid [24]. Reducing proteinuria independent of other progression mechanisms would be essential to address the hypothesis that proteinuria causes progression of diabetic nephropathy [111]. Targeting proteinuria reduction in patients with established diabetic nephropathy in order to slow renal progression is generally accomplished with agents that reduce both proteinuria and blood pressure [112]. A broad range of therapeutic interventions to either reduce proteinuria or block the damaging effects of proteinuria (table 2) has been recently reviewed [111]. Data are very limited on therapies which might reduce proteinuria through other mechanisms unrelated to blood pressure reduction on RAS blockade $[113,114]$. In the ACTION 1 study of the advanced glycation end product inhibitor pimagedine, significant reductions in proteinuria occurred compared to placebo, independent of changes in blood pressure, despite the nearly universal use of ACEI/ARBs in pimagedine- and placebo-treated patients. Patients with stable or decreased proteinuria experienced fewer instances of doubling of creatinine levels. However, the AGE inhibitor failed to produce a statistically significant overall reduction in the primary endpoint of doubling of serum creatinine in the study [113].

In nondiabetic kidney disease, data supporting a relationship between early reductions in proteinuria and slower renal progression have emerged, exclusively from secondary analyses of clinical trials [74, 115]. A recent post hoc analysis of the African American Study of Kid- ney Disease (AASK) trial has added new information [116] by assessing the initial reduction in proteinuria (6 months vs. baseline) as a predictor of decline in the glomerular filtration rate. Enrolled patients had been randomized to different levels of mean arterial pressure (102-107 vs. $\leq 92 \mathrm{~mm} \mathrm{Hg}$ ) and to different antihypertensive treatment groups. Similar to the relationship to the baseline level of proteinuria, the decline in glomerular filtration rate and risk of ESRD were strongly predicted by the initial change in proteinuria in this nondiabetic study of patients with hypertensive nephrosclerosis. The association of proteinuria change with subsequent progression of kidney disease was present regardless of baseline levels of proteinuria (an initial urine protein-to-creatinine ratio of $>2.5$ was an entry exclusion to the trial).

In the recently published COOPERATE-ABP substudy, about one third of patients enrolled in the original COOPERATE trial (randomized to ACEI, ARBs, or combination therapy) for nondiabetic kidney disease underwent ambulatory blood pressure monitoring [117]. Superior sustained proteinuria reduction (74\%) in the combination group was associated with the least number of patients reaching the renal endpoints of creatinine doubling or ESRD.

\section{Treatment of Hypertension}

Hypertension affects up to $60 \%$ of diabetic patients and increases the risk of microvascular complications such as nephropathy $[22,112,118]$. Hypertension occurs early [119], and it is the major determinant of the rate of nephropathy progression [120]. Both cross-sectional and longitudinal studies have identified a correlation between hypertension and decline in renal function in type 2 patients [121-123], although the relationship between hypertension and type 1 and type 2 nephropathy may not be identical [124]. In patients with type 1 diabetes, the onset of microalbuminuria and its progression to overt nephropathy are associated with a higher level of blood pressure, and the relationship between hypertension and renal progression is clearly established [125]. In the majority of type 2 diabetic nephropathy patients, abnormal circadian blood pressure patterns or overt hypertension are already present prior to proteinuria. Compared to the normal renal vasoconstrictive autoregulatory response to hypertension, diabetic patients are less able to vasoconstrict the afferent arteriole, allowing hypertension to elevate glomerular capillary pressures, in association with greater degrees of proteinuria [125].

Early reports that effective antihypertensive treatment in diabetic nephropathy reduced albuminuria [126] and 
the risk of renal progression $[127,128]$ have been validated [129]. Aggressive early antihypertensive therapy reduces proteinuria in patients with type 1 diabetic nephropathy [21] and greater reductions may occur in patients who still have hyperfiltration [130]. With slowing of renal progression, proteinuria decreases, and the most significant reductions in proteinuria are associated with the largest reductions in blood pressure [131-133]. Following initiation of antihypertensive therapy in hypertensive patients with diabetic nephropathy, a faster initial reduction in glomerular filtration is followed by a slower sustained decline [134]. It should be noted that initiation of antihypertensive treatment results in an initial drop in function, regardless of the antihypertensive agent used. A recent ACEI study using varying doses of ramipril as the primary antihypertensive agent showed that proteinuria was reduced in a group with a mean arterial pressure of $92 \mathrm{~mm}$ $\mathrm{Hg}$, but rose in the group with mean pressures only $8 \mathrm{~mm}$ $\mathrm{Hg}$ higher [135]. Reductions in systemic pressure are associated with lowering of glomerular capillary pressure. When systemic blood pressure is lowered $10-20 \%$, ACE inhibitors, some calcium channel blockers (CCBs), and even conventional therapy with beta blockers or diuretics all have significant antiproteinuric effects [136, 137]. The most significant reductions in proteinuria have occurred in studies with the largest reductions in blood pressure [125]. However, the antiproteinuric effects of antihypertensive agents of different classes do vary considerably [21]. In contrast to significant reductions in protein excretion associated with ACEI/ARBs, for example, nondihydropyridine (NDHP) CCBs cause a milder decline, and dihydropyridine (DHP) calcium blockers and beta blockers no apparent reduction, apart from their hypotensive actions [138]. The different effects of classes of antihypertensive agents on proteinuria are likely due to different actions on hemodynamics or metabolism [136, 138]. Other modifying factors are the patient's salt intake and levels of aldosterone in the circulation. While drug-specific effects may dominate pressure-dependent influences on proteinuria, patients responding to one class of drug frequently also benefit from other classes.

\section{Angiotensin-Converting Enzyme Inhibitor}

Beyond their antihypertensive benefit, ACEI slow the progression of type 1 diabetic nephropathy [139, 140]. The mechanisms of the beneficial nephroprotective activity of RAS inhibition in diabetic nephropathy are complex and still incompletely understood $[24,140,141]$ and may vary somewhat between type 1 and type 2 diabetes. Operative actions (table 3 ) include systemic and intrare-
Table 3. Operative actions of angiotensin blockade to reduce proteinuria

Decrease systemic pressure

Decrease glomerular permeability

Decrease fractional mesangial volume

Decrease extracellular matrix components

Decrease filtration of proteins across glomerular capillary wall

Restore glomerular basement pore size distribution

Normalize nephrin gene expression

Decrease monocyte chemoattractant protein-1

nal hemodynamic effects, improvements in the filtration barrier itself, and blockade of angiotensin II's growthstimulating actions that promote tissue fibrosis and extracellular expansion [142]. A recent human biopsy study indicated that renin-angiotensin components including the ACE and angiotensin II were present in tubulointerstitial compartments, indicative of elevated local angiotensin production associated with induction of proinflammatory parameters which were measured [143]. ACEI are known to reduce proteinuria in type 1 diabetic nephropathy by diminishing the size of large nonselective pores in the glomerular filtration barrier [144]. Recent data suggest that zona occludens- 1 , which plays a critical role in maintaining function of the epithelial slit diaphragm, is altered in experimental diabetic nephropathy, and that ACEI prevent the alteration [145]. In streptozotocin-treated rats with proteinuria, reduced nephrin gene expression is attenuated with ACE inhibition [146]. Other data indicate that ACEI do not correct the size-selective basement membrane dysfunction in type 2 diabetes, although other renal structural abnormalities, including interstitial expansion, may benefit [147].

Nearly 20 years have elapsed since the initial reports that converting enzyme inhibitors reduced severe proteinuria in diabetic nephropathy [148] independent of a fall in blood pressure. Subsequent studies have indicated that reduction in proteinuria is associated with slowing of renal progression in patients with overt nephropathy. ACEI reduce the level of proteinuria more than equivalent doses of other classes of antihypertensive agents do, similar to their impact on serum creatinine $[149,150]$ but the proteinuria advantage is lost as the systemic blood pressure declines $[10,136]$. Event rates in clinical trial comparisons between ACEI and placebo become identical once treatments lower systemic blood pressure to means of less than $95 \mathrm{~mm} \mathrm{Hg}$ [125]. The initial decrease in proteinuria with ACEI, which occurs within weeks of 
therapy, may be largely functional in nature. However, the nadir in proteinuria may require a year of ACEI therapy. A small subset of patients treated in a clinical trial setting appears to achieve proteinuria remission, and renal decline becomes nonprogressive [151].

The clinical benefit to reduce proteinuria appears to be less significant in type 2 diabetic nephropathy [42]. The results of ACEI remain inconclusive [104, 152, 153]. While beneficial effects on proteinuria have been demonstrated with ACEI, no prospective, controlled study has demonstrated a similar benefit on definite renal functional endpoints in type 2 patients [125]. Genetic variation in patients is one of many factors under evaluation to explain heterogeneous responses to RAS blockade [154]. Whether drug-related reductions or remissions in proteinuria can be interpreted as demonstrating 'renal protection' remains unclear, and a specific goal for proteinuria reduction has not been established by studies in either type 1 or type 2 diabetic nephropathy patients.

\section{Angiotensin Receptor Blockers}

Whether the ARBs were renoprotective in human diabetic nephropathy became the subject of two large clinical trials in the past decade. The differential effects of ARBs, in comparison to ACEI, have been reviewed elsewhere $[155,156]$. Reduction of AT1 receptor stimulation by its ligand angiotensin II is the main action common to both ACEI and ARBs. The main differences are the blockade of bradykinin degradation by ACEI and the unopposed activation of the AT2 receptors when ARBs are utilized. Limited available data comparing the effects of ACEI and ARBs in diabetic nephropathy suggest similar effects on macroalbuminuria [157-159]. Comparative data on overt proteinuria are limited. Andersen et al. [158] reported comparable reduction of albuminuria between the ACEI enalapril and the ARB losartan in a double-blind, randomized crossover study in type 1 diabetic nephropathy. Additional investigation showed that the ARB reduced the abnormally elevated size-selective properties of the glomerular basement membrane in the diabetic kidney. AT1 receptor antagonists appear to be better tolerated than ACEI.

These differential effects of ARBs in comparison to ACEI formed the basis of the IDNT and RENAAL studies. In the RENAAL study, 1,513 patients with type 2 diabetic nephropathy were randomized to losartan or placebo for a mean of 3.4 years, in addition to conventional antihypertensive therapy [106]. The ARB reduced the incidence of serum creatinine doubling (risk reduction $25 \%$ ) and ESRD (risk reduction 28\%), and was associated with an average $35 \%$ reduction in proteinuria. Placebotreated patients experienced a slight increase in the median change in proteinuria from baseline during the study. The initial (first 6 months) antiproteinura response to ARB therapy and the reduction in albuminuria due to losartan were recently reported [110]. Albumin was reduced by $28 \%$ from baseline in the losartan group in the first 6 months of the study, although the change in albumin in both groups was highly variable. Significant (23\%) reduction in albuminuria was associated with a beneficial effect on renal protection even when correcting for other differences in risk factors. Furthermore, when residual albuminuria was adjusted for, the treatment effect of losartan on the renal endpoint was eliminated. These analyses of baseline and therapy-induced changes in albuminuria provide firm new evidence that albuminuria should be a primary target of therapy in type 2 diabetic patients with nephropathy.

The IDNT, the second randomized, double-blind, placebo-controlled study, also demonstrated the benefit of RAS inhibition with angiotensin II receptor blockers in hypertensive type 2 diabetic patients with overt nephropathy (900 mg proteinuria per day) [105]. The composite primary endpoint was doubling of the baseline serum creatinine level, development of ESRD (dialysis, transplantation, or serum creatinine $\geq 6.0 \mathrm{mg} / \mathrm{dl}$ ), or death from any cause. Enrollment criteria were $1.0-3.0 \mathrm{mg} / \mathrm{dl}$ in females and $1.2-3.0 \mathrm{mg} / \mathrm{dl}$ in males. Study patients were taken off all ACEI, ARBs, and CCBs, and randomized to irbesartan $300 \mathrm{mg}$, amlodipine $10 \mathrm{mg}$ daily, or placebo. After a mean follow-up of 2.6 years, irbesartan risk reduction was $20 \%$ versus placebo $(p=0.02)$ and $23 \%$ versus amlodipine $(p=0.006)$. Specific risk reduction for serum creatinine doubling was 33\% with irbesartan versus placebo $(\mathrm{p}=0.003)$ and $37 \%$ versus amlodipine $(\mathrm{p}<0.001)$. Similar irbesartan risk reduction was found for ESRD progression, but not for mortality outcomes. Post hoc unpublished analysis indicated that risk reduction was related to baseline proteinuria: patients with nephrotic proteinuria had an event rate of $70 \%$ and a 14 -fold increased risk of progression to advanced disease [154]. Mean baseline urinary protein excretion was $2.9 \mathrm{~g} / 24 \mathrm{~h}$ in all groups. Treatment with irbesartan was associated with a $33 \%$ reduction in 24-hour urinary protein excretion, compared with $6 \%$ in the amlodipine group and $10 \%$ in the placebo group. Results of the RENAAL and IDNT studies demonstrating benefit of ARBs in progression of overt nephropathy in type 2 diabetes have led to regulatory drug approval for ARBs in initial therapy for hypertensive type 2 diabetic patients with proteinuric renal disease. 


\section{Combination Therapy}

Effects to maximize the antiproteinuric effect of ACEI or ARBs include dietary salt restriction and addition of a diuretic [158]. The therapeutic advantage of combination ACEI/ARB therapy for nondiabetic renal disease has recently been reported [160]. The theoretical benefits of combination therapy include those of ACEI (decreased angiotensin II levels, increased bradykinin, depressed aldosterone) added to those of ARB therapy (blockade of angiotensin II produced by chymase, increased vasodilatory, antiproliferatative and antifibrotic effects) [161]. Examination of the RENAAL and IDNT data reveal that while renal progression was reduced, over $40 \%$ of those on losartan and over $30 \%$ of those on irbesartan reached primary endpoints [162]. With complementary biological mechanisms, dual blockade with ACEI and ARBs for diabetic proteinuria has theoretical advantages over monotherapy $[163,164]$.

In addition, in the nephropathy patient at high risk for cardiovascular complications, dual blockade offers cardiovascular as well as renal protection. Both ACEI and ARBs are associated with improved cardiovascular outcomes in clinical trials. Several studies, summarized recently [165], analyzing the effects of RAS inhibition on the risk of cardiovascular complications in study populations that included diabetics, have been reported. Favorable results on a composite of major cardiovascular events has been shown with ACEI [166] while similar protection may be achieved with ARB therapy [167-169]. Limited data are available comparing cardiovascular benefits of ACEI versus ARBs [170, 171]. Until the issue is resolved, a strategy of dual blockade has been suggested [165].

Little is known about the comparable effects of ACEI and ARBs on proteinuria in patients with overt diabetic nephropathy $[172,173]$. Data in nondiabetic renal disease [174] suggest that combination therapy might synergistically reduce proteinuria levels. However, data comparing dual blockade with equivalent blocking doses of either class, or with the ARB/ACEI used with another agent, in groups with comparable blood pressures, are not available. It is likely that combination therapy will preclude use of maximal doses of either class of agents in the clinical setting [175].

\section{Calcium Channel Blockers}

While ACEI and ARBs are the most effective antiproteinuria agents for diabetic nephropathy, additional therapy may be necessary to meet the currently recommended blood pressure targets. In addition, a rise in serum creatinine of more than $35 \%$ above baseline or the emergence of hyperkalemia may be a reason to withhold firstline ACEI or ARB therapy [176, 177]. CCBs are among the most commonly used classes of antihypertensive drugs in patients with kidney disease [178]. However, evidence for any renoprotective effects of calcium antagonists is equivocal. DHP and NDHP CCBs have differential effects on proteinuria. A systematic review of 28 randomized clinical trials in hypertensive proteinuric adults with or without diabetes that included a DHP or NDHP treatment arm was recently published by Bakris et al. [179]. NDHP CCBs alone or in combination with an ACEI or ARB produced significant reductions in proteinuria, compared to no antiproteinuric effects in DHP CCBs, in the presence or absence of diabetes. NDHP CCBs appear to have properties that affect glomerular permselectivity differently than DHP CCBs [180], not directly related to blood pressure reductions. When used in combination with ACEI in type 2 diabetes, NDHP CCBs induce a greater reduction in proteinuria than DHP CCBs [181]. A recent study in nondiabetic nephropathy of either the NDHP verapamil or the DHP amlodipine with an ACEI suggested that the DHP CCB had an adverse effect on selectivity of proteinuria [178].

\section{The Surrogate Endpoint}

According to the third postulate of the proteinuria hypothesis, proteinuria is a potential surrogate endpoint for current outcome measures [182, 183], and diabetic nephropathy is a disease model for the potential use of proteinuria as a surrogate [2]. In chronic kidney disease, trials to evaluate new drug treatments have traditionally been required to use recognized 'hard' endpoints of dialysis, transplantation, and death rates, for regulatory approval [184]. These have been combined more recently with the 'first generation' surrogate marker, doubling of serum creatinine, over the course of the trial. The use of the serum creatinine surrogate has allowed studies to show benefit with smaller sample sizes over a reduced drug exposure time [185] even at an intermediate stage of disease severity, where composite 'hard' endpoints less frequently occur. However, because changes in serum 
creatinine are less sensitive in the earliest stages of kidney disease progression, prohibitively large early intervention trials of longer duration will again be required [186], making creatinine impractical as the sole outcome marker.

Insofar as early intervention is critical [26] in diabetic nephropathy, a valid earlier ('second generation') surrogate marker with effects proportional to accepted endpoints would be particularly valuable [12]. While it is an appropriate measure in patients with more advanced disease undergoing decline in renal function over months, the creatinine rise may be prohibitively slow in early stages of diabetic nephropathy. Furthermore, disease progression as measured by creatinine doubling may be slowest, with low event rates, in the earliest stages of the disease, when intervention might be most successful. The selection of a surrogate outcome would require a clinical connection between the surrogate and the established outcome in the context of the disease and intervention under investigation.

In the case of proteinuria, disadvantages include the intrasubject variability in proteinuria, uncertainty regarding meaningful reduction in proteinuria, and the lack of 'breakthrough' drugs with isolated antialbuminuric or antiproteinuric effects to be tested. Studies utilizing proteinuria as a primary outcome measure linked to secondary harder endpoints for new drug approval are currently lacking. The above analysis indicates that the relationship of albuminuria and proteinuria to the course of diabetic nephropathy is complex. Strict interpretation of available data on RAS blockade does suggest that albumin should be reduced to minimal achievable levels in diabetic nephropathy. While proteinuria reduction would be advan- tageous as a new surrogate outcome measure to facilitate regulatory drug evaluation, this postulate is likely to depend on factors specific to the diseases and the drugs used.

\section{Conclusion}

Overt diabetic nephropathy is characterized by proteinuria and progressive loss of kidney function, and treatment to delay progression now includes strict control of proteinuria. Complex mechanisms altering the protein-selective glomerular basement membrane exist in diabetic nephropathy, and form the targets of current therapies. Large clinical studies support an overall relationship between severity of albuminuria or proteinuria and rate of progression in diabetic nephropathy. The benefit of albuminuria reduction, at least by RAS blockade, to minimum goals in diabetic nephropathy, is emerging. While diabetic kidney disease is a paradigm for proteinuria as a surrogate marker for renal function in the drug approval process, this shift in perspective will require prospective data from additional clinical trials, particularly of non-RAS drugs, to be complete. More needs to be learned about human diabetic nephropathy before the proteinuria hypothesis can be fully adopted.

\section{Acknowledgments}

The author wishes to express gratitude to Dr. Richard Solomon and Dr. Franklin H. Epstein for their expert review of the manuscript.

\section{References}

1 Gregg EW, Cadwell BL, Cheng YJ, et al: Trends in the prevalence and ratio of diagnosed to undiagnosed diabetes according to obesity levels in the U.S. Diabetes Care 2004; 27:2806-2812.

$\checkmark 2$ Hostetler TH: Prevention of end-stage renal disease due to type 2 diabetes. N Engl J Med 2001;345:910-911.

-3 Mohanram A, Todo RD: Outcome studies in diabetic nephropathy. Semin Nephrol 2003; 23:255-271

$\checkmark 4$ Caramori ML, Mauer M: Diabetes and nephropathy. Curr Opin Nephrol Hypertens 2003; 12:273-282.

5 Saydah SH, Fradkin J, Cowie CC: Poor control of risk factors for vascular disease among adults with previously diagnosed diabetes. JAMA 2004;291:335-342.
6 ADA: Standards of medical care for patients with diabetes mellitus. Diabetes Care 2002; 25(S1):S33-S49.

7 Gordois A, Scuffham P, Shearer A, et al: The health care costs of diabetic nephropathy in the United States and the United Kingdom. J Diabetes Complications 2004;18:18-26.

$>8$ Burton G, Harris KPG: The role of proteinuria in the progression of chronic renal failure. Am J Kindney Dis 1996;27:765-776.

9 Watkins PJU, Blainey JD, Brewer DB, et al: The natural history of diabetic renal disease. Q J Med 1972;41:437-456.

10 Ritz E, Orth SO: Neprhopathy in patients with type 2 diabetes mellitus. N Engl J Med 1999; 341:1127-1133.
11 Garg AX, Kiberd BA, Clark WF, et al: Albuminuria and renal insufficiency prevalence guides population screening: Results from the NHANES II. Kidney Int 2002;61:2165-2175.

12 Campbell RC, Ruggenenti P, Remuzzi G: Proteinuria in diabetic nephropathy: Treatment and evolution. Curr Diab Rep 2003;3:497504.

13 Warram JH, Krolewski AS: Use of the albu$\mathrm{min} /$ creatinine ratio in patient care and clinical studies; in Morgensen CE (ed): The Kidney and Hypertension in Diabetes Mellitus. Boston, Kluwer Academic Publ., 1998, pp 85-96.

$>14$ Klein R, Klein BEK, Moss SE: The incidence of gross proteinuria in people with insulin-dependent diabetes mellitus. Arch Intern Med $1991 ; 151: 1344-1348$ 
15 Perkins BA, Ficociello LH, Silva KH, et al: Regression of microalbuminuria in type 1 diabetes. N Engl J Med 2003;5:2285-2293.

16 Caramori M, Luiza F, Mauer M: The need for early predictors of diabetic nephropathy risk: Is albumin excretion rate sufficient? Diabetes 2000;49:1399-1408.

17 Wilmer WA, Rovin BH, Herbert CJ, et al: Management of glomerular proteinuria: A commentary. J Am Soc Nephrol 2003; 14: 3217-3232.

18 Myers BD, Winetz JA, Chui F, Michaels AS: Mechanisms of proteinuria in diabetic nephropathy: A study of glomerular barrier function. Kidney Int 1982;21:633-641.

19 Mogensen CE, Christensen CK, Vittinghus E: The stages in diabetic renal disease. With emphasis on the stage of incipient diabetic nephropathy. Diabetes 1983;32:64-78.

20 Mogensen CE: Microalbuminuria as a predictor of clinical diabetic nephropathy. Kidney Int 1987;31:673-689.

21 Parving H-H: Diabetic nephropathy: Prevention and treatment. Kidney Int 2001;60:20412055.

-22 Brever JA, Bain RP, Evans JK, Nahman NS, Lewis EJ, Cooper M, McGill J, Berl T: Predictors of the progression of renal insufficiency in patients with insulin-dependent diabetes and overt nephropathy. Kidney Int 1996;50:16511658.

-23 Yu HT: Progression of chronic renal failure. Arch Intern Med 2003;153:1417-1429.

24 Brenner BM: Retarding the progression of renal disease. Kidney Int 2003;64:370-378

$\checkmark 25$ Woo KT, Lau YK: Proteinuria: Clinical significance and basis for therapy. Singapore Med J 2001;42:385-389.

- 26 Eknoyan G, Hostetter T, Bakris GL, et al: Proteinuria and other markers of chronic kidney disease: A position statement of the national kidney foundation (NKF) and the national institute of diabetes and digestive and kidney diseases (NIDDK). Am J Kidney Dis 2003;42: 617-622.

$\checkmark 27$ Writing Team for the Diabetes Control and Complications Trial/Epidemiology of Diabetes Interventions and Complications Research Group: Sustained effect of intensive treatment of type 1 diabetes mellitus on development and progression of diabetic nephropathy. JAMA 2003;290:2159-2167.

-28 Tryggvason K, Pettersson E: Causes and consequences of proteinuria: The kidney filtration barrier and progressive renal failure. J Intern Med 2003;254:216-224.

-29 Brenner BM, Hostetter T, Humes HD: Molecular basis of proteinuria of glomerular origin. N Engl J Med 1978;298:826-833.

30 Ritz E: Albuminuria and vascular damage the vicious twins. N Engl J Med 2003;348: 2349-2352.

- 31 Garg JP, Bakris GL: Microalbuminuria: Marker of vascular dysfunction, risk factor for cardiovascular disease. Vasc Med 2002; 7:35-43.

-32 Stuveling EM, Bakker SJL, Hillege HL, et al: C-reactive protein modifies the relationship between blood pressure and microalbuminuria. Hypertension 2004;43:791-797.
33 Mora C, Navarro JF: Inflammation and pathogenesis of diabetic nephropathy. Metabolism 2004;53:266-267.

34 Wolf G, Ziyadeh FN: The role of angiotensin II in diabetic nephropathy: Emphasis on nonhemodynamic mechanisms. Am J Kidney Dis 1997;29:153-163.

35 Amann B, Tinzmann R, Angelkort B: ACE inhibitors improve diabetic nephropathy through suppression of renal MCP-1. Diabetes Care 2003;26:2421-2425

36 Cao Z, Cooper ME, Wu LL, et al: Blockade of the rennin-angiotensin system and endothelin systems on progressive renal injury. Hypertension 2000;36:561-568.

37 Bijol V, Silver SM, Nadasdy T: A 65-year-old diabetic man with progressive renal insufficiency and proteinuria. Am J Kidney Dis 2002; 40:429-434.

38 Drummond K, Mauer M; International Diabetes Nephropathy Study Group: The early natural history of nephropathy in type 1 diabetes. II. Early renal structural changes in type 1 diabetes. Diabetes 2002;51:1580-1587.

- 39 Fioretto P, Steffes MW, Sutherland DE, et al: Sequential renal biopsies in insulin-dependent diabetic patients: Structural factors associated with clinical progression. Kidney Int 1995;48: 1929-1935.

40 Nosadini R, Tonolo G: Cardiovascular and renal protection in type 2 diabetes mellitus: The role of calcium channel blockers. J Am Soc Nephrol 2002;13:S216-S223.

41 Deen WM: What determines glomerular capillary permeability? J Clin Invest 2004;114 1412-1414.

42 Ruggenenti P, Perna A, Beneni R, et al: In chronic nephropathies prolonged ACE inhibition can induce remission: Dynamics of timedependent changes in GFR. J Am Soc Nephrol 1999; 10:997-1006.

43 Hostetter TH: Mechanisms of diabetic nephropathy. Am J Kidney Dis 1994;23:188192.

44 Noth RH, Krolewski AS, Kaysen GA, et al: Diabetic nephropathy: Hemodynamic basis and implications for disease management. Ann Intern Med 1989;220:795-813.

45 Steffes MW, Schmidt D, McCrery R, et al: Glomerular cell number in normal subjects and in type 1 diabetic patients. Kidney Int 2001;59: 2104-2013.

46 Cohen AH, Mampaso F, Zamboni L: Glomerular podocyte degeneration in human renal disease. An ultrasound study. Lab Invest 1977; 37:40-42.

47 Pagtalunan ME, Miller Pl, Jumping-Eagle S, et al: Podocyte loss and progressive glomerular injury in type 2 diabetes. J Clin Invest 1997; 99:342-348

48 Vestra MD, Masiero A, Roiter AM, et al: Is podocyte injury relevant in diabetic nephropathy? Diabetes 2003;52:1031-1035.

49 Kim JM, Wu H, Green G, et al: CD2-associated protein haloinsufficiency is linked to glomerular disease susceptibility. Science 2003; 300:1298-1300.
50 Huber TB, Reinhardt C, Simons M, et al: Direct binding of cholesterol and targeting of nephrin to lipid rafts are disrupted in diseasecausing podocin mutations. J Am Soc Nephrol 2004; $15: 33$ A

51 Adler S: Diabetic nephropathy: Linking histology, cell biology, and genetics. Kidney Int 2004;66:2095-2106.

$>52$ Beltcheva O, Kontusaari S, Fetissov S, et al: Alternatively used promoters and distinct elements direct tissue-specific expression of nephrin. J Am Soc Nephrol 2003;14:352-358.

53 Caridi G, Bertelli R, DiDuca M, et al: Broadening the spectrum of diseases related to podocin mutations. J Am Soc Nephrol 2003;14:12781286.

54 Bonnet F, Cooper ME, Kawachi H, et al: Irbesartan normalizes the deficiency in glomerular nephrin expression in a model of diabetes and hypertension. Diabetologia 2001;44:874-877.

55 Forbes JM, Bonnet F, Russo LM, et al: Modulation of nephrin in the diabetic kidney: Association with systemic hypertension and increasing albuminuria. J Hypertens 2002;20: 985-992.

56 Cooper ME, Mundel P, Boner G: Role of nephrin in renal disease including diabetic nephropathy. Semin Nephrol 2002;22:393-398.

57 Mifsud SA, Allen TJ, Bertram JF, et al: Podocyte foot process broadening in experimental diabetic nephropathy: Amelioration with renin-angiotensin blockade. Diabetologia 2001; 44:878-882.

58 Kelly DJ, Aaltonen P, Cox AJ, et al: Expression of the slit-diaphragm protein, nephrin, in experimental diabetic nephropathy: Differing effects of anti-proteinuric therapies. Nephrol Dial Transplant 2002;17:1327-1332.

59 Doublier S, Salvidio G, Lupia E, et al: Nephrin expression is reduced in human diabetic nephropathy. Diabetes 2003;52:1023-1030.

60 Langham RG, Kelly DJ, Cox AJ, et al: Proteinuria and the expression of the podocyte slit diaphragm protein, nephrin, in diabetic nephropathy: Effects of angiotensin converting enzyme inhibition. Diabetologia 2002; 45: 1572-1576.

61 Toyoda M, Suzuki D, Umezono T, et al: Expression of human nephrin mRNA in diabetic nephropathy. Nephrol Dial Transplant 2004; 19:380-385.

62 Baelde HJ, Eikmans M, Doran PP, et al: Gene expression profiling in glomeruli from human kidneys with diabetic nephropathy. Am J Kidney Dis 2004;43:636-650.

63 Benigni A, Gagliardini E, Tomasoni S, et al: Selective impairment of gene expression and assembly of nephrin in human diabetic nephropathy. Kidney Int 2004;65:2193-2200.

64 Pettersson-Fernholm K, Forsblom C, Perola $\mathrm{M}$, et al: Polymorphisms in the nephrin gene and diabetic nephropathy in type 1 diabetic patients. Kidney Int 2003;63:1205-1210.

65 National Kidney Foundation: K/DOQI Clinical Practice Guidelines for Chronic Kidney Disease: Evaluation, Classification, and Stratification: Guideline 5-Assessment of Proteinuria. Am J Kidney Dis 2002;39:S93-S102. 
66 Russo LM, Bakris GL, Comper WD: Renal handling of albumin: A critical review of basic concepts and perspective. Am J Kidney Dis 2002;39:899-919.

67 Comper WD, Osicka TM, Clark M, et al: Earlier detection of macroalbuminuria in diabetic patients using a new urinary albumin assay. Kidney Int 2004;65:1850-1855.

68 Grieve KA, Balazs N, Comper WD: Protein fragments in urine have been considerably underestimated by various protein assays. Clin Chem 2001;47:1717-1719.

-69 Viberti GC, Nackintosh D, Bilous RW, et al: Proteinuria in diabetes mellitus: Role of spontaneous and experimental variation of glycemia. Kidney Int 1982;21:714-720.

70 Gilbert RE, Copper ME: The tubulointerstitium in progressive diabetic kidney disease: More than an aftermath of glomerular injury? Kidney Int 1999;56:1627-1637.

71 Eddy AA: Experimental insights into the tubulointerstitial disease accompanying primary glomerular lesions. J Am Soc Nephrol 1994;5: 1273-1287.

72 Remuzzi G, Ruggenenti P, Benigni A: Understanding the nature of renal disease progression. Kidney Int 1997;51:2-15.

73 Bazzi C, Petrini C, Rizza, et al: A modern approach to selectivity of proteinuria and tubulointerstitial damage in nephritic syndrome. Kidney Int 2001;59:1595-1597.

74 Jafar TH, Stark PC, Schmid CH, et al; AIPRD Study Group: Proteinuria as a modifiable risk factor for the progression of non-diabetic renal disease. Kidney Int 2001;60:1131-1140.

75 Burton G, Harris KPG: The role of proteinuria in the progression of chronic renal failure. Am J Kidney Dis 1996;27:765-775.

-76 Hebert LA, Silmer WA, Falkenhain ME: Renoprotection: One or many therapies? Kidney Int 2001;59:1211-1226.

77 Fogo AB: Progression and potential regression of glomerulosclerosis. Kidney Int 2001;59: 804-819.

78 Endlich K, Kriz W, Witzgall R: Update in podocyte biology. Curr Opin Nephrol Hypertens 2001; 10:331-340.

79 Jerums G, Panagiotopoulos S, Tsalamandris $\mathrm{C}$, et al: Why is proteinuria such an important risk factor for progression in clinical trials? Kidney Int Suppl 1997;63:S87-S92.

-80 Nakkajima H, Takenaka M, Kaimori JY: Gene expression profile of renal proximal tubules regulated by proteinuria. Kidney Int 2002;61: 1577-1587.

-81 Wang Y, Rangan GK, Tay Y-C, et al: Induction of monocyte chemoattraction protein- 1 by albumin is mediated by nuclear factor $\mathrm{\kappa B}$ in proximal tubule cells. J Am Soc Nephrol 1994; 10:1204-1213.

82 Gruden G, Thomas S, Burt D, et al: Mechanical stretch induces vascular permeability factor in human mesangial cells: Mechanisms of signal transduction. Proc Natl Acad Sci USA 1997;94:12112-12116.

83 Kimmelstiel P, Wilson C: Intercapillary lesions in glomeruli of kidney. Am J Pathol 1936; 12:83-98.
84 Mogensen CE, Christensens CK, Vittinghus D: The stages of diabetic renal disease, with emphasis on the stage of incipient diabetic nephropathy. Diabetologia 1983;32(S2):64-78.

85 Ciavarella A, Di Mizio G, Stefoni S, et al: Reduced albuminuria after dietary protein restriction in insulin-dependent diabetic patients with clinical nephropathy. Diabetes Care 1987; 10:407-413.

86 Mogensen CE, Christensen CK: Predicting diabetic nephropathy in insulin-dependent patients. N Engl J Med 1984;311:89-93.

87 Parving H-H, Smidt UV, Friisberg B, et al: A prospective study of glomerular filtration rate and arterial blood pressure in insulin-dependent diabetics with diabetic nephropathy. Diabetologia 1981;20:457-461.

88 Goldstein DA, Massry SG: Diabetic nephropathy. Clinical course and effect of hemodialysis. Nephron 1978;20:286-296.

89 Christiansen CK, Mogensen CE: The course of incipient diabetic nephropathy: Studies of albumin excretion and blood pressure. Diabet Med 1985;2:97-102.

90 Mogensen CE, Christensen CK, Vittinghus D: The stages of diabetic renal disease, with emphasis on the stage of incipient diabetic nephropathy. Diabetes 1983;32:64-87.

91 Carrie BJ, Myers BD: Proteinuria and functional characteristics of the glomerular barrier in diabetic nephropathy. Kidney Int 1980;17: 669-676.

92 Viberti GC, Mackintosh D, Bilous RW, et al. Proteinuria in diabetes mellitus: Role of spontaneous and experimental variation of glycemia. Kidney Int 1982;21:714-720.

93 DiMario U, Morano S, Cancelli A: New parameters to monitor the progression of diabetic nephropathy. Am J Kidney Dis 1989;13: 45-48.

94 Hostetter TH, Rennke HG, Brenner BM: The case for intrarenal hypertension in the initiation and progression of diabetic and other glomerulopathies. Am J Med 1982;72:375-380.

$>95$ Keane WF, Eknoyan G: Proteinuria, albuminuria, risk, assessment, detection, elimination (PARADE): A position paper of the National Kidney Foundation. Am J Kidney Dis 1999; 33:1004-1010.

96 Rossing P, Hommel E, Smidt UM, et al: Reduction in albuminuria predicts a beneficial effect on diminishing the progression of diabetic nephropathy during antihypertensive treatment. Diabetologia 1994;37:511-516.

97 Locatelli F, Del Vecchio L, D'Amico M, et al Is it the agent or the flood pressure level that matters for renal protection in chronic nephropathies? J Am Soc Nephrol 2002;13: S196-S201.

98 Hunsicker LG, Adler S, Caggiula A, England BK, Greene T, Kusek JW, Rogers NL, Teschan PE: Predictors of the progression of renal disease in the Modification of Diet in Renal Disease Study. Kidney Int 1997;51:1908-1919.

$>99$ Wright JT, Bakris G, Greene T, et al: Effect of blood pressure lowering and antihypertensive drug class on progression of hypertensive kidney disease: Results from the AASK trial. JAMA 2002;288:2421-2431.
100 Bos H, Andersen S, Rossing P, et al: Role of patient factors in therapy resistance to antiproteinuric intervention in nondiabetic and diabetic nephropathy. Kidney Int 2000;57: S32-S37.

101 Williams PS, Fass G, Bone JM: Renal pathology and proteinuria determine progression in untreated mild/moderate chronic renal failure. Q J Med 1988;67:343-354.

102 Gellman DD, Pirani CC, Soothil JE, et al: Diabetic nephropathy: A clinical-pathological study based on renal biopsies. Medicine 1959;38:321-347.

103 Appel G, Bolton K, Freedman B, et al: Pimagedine lowers total urinary protein and slows progression of overt diabetic nephropathy in patients with type 1 diabetes (abstract). J Am Soc Nephrol 1999;10:153A.

104 Lebovitz HE, Wiegmann TB, Cnaan A, et al: Renal protective effects of enalapril in hypertensive NIDDM: Role of baseline albuminuria. Kidney Int 1994;45(S45):S150-S155.

105 Lewis EJ, Hunsicker LG, Clarke WR, Berl T, Pohl MA, Lewis JB, Ritz E, Atkins RC, Rohde R, Raz I: Renoprotective effect of the angiotensin-receptor antagonist irbesartan in patients with nephropathy due to type 2 diabetes. N Engl J Med 2001;345:851-860.

106 Brenner BM, Cooper ME, DeZeeuw D, Keane WF, Mitch WE, Parving H-H, Remuzzi G, Snappin SM, Zhang Z, Shafinfar S; RENAAL Study Investigators: Effects of losartan on renal and cardiovascular outcomes in patients with type 2 diabetes and nephropathy. N Engl J Med 2001;345:861-869.

107 Weir MR: Diabetes and hypertension: How low should you go and with which drugs? Am J Hypertens 2001; 14:17s-26s.

108 Bakris GL, Weir MR, Shanifar S, et al: Effects of blood pressure level on progression of diabetic nephropathy. Results from the RENAAL study. Arch Intern Med 2003; 163 : 1555-1565.

109 Keane WF, Lyle PA: Recent advances in management of type 2 diabetes and nephropathy: Lessons from the RENAAL study. Am J Kidney Dis 2003;41(S3):S22-S25.

110 DeZeeuw D, Remuzzi G, Parving H-H, et al: Proteinuria, a target for renoprotection in patients with type 2 diabetic nephropathy: Lessons from RENAAL. Kidney Int 2004;65: 2309-2320.

111 Wilmer WA, Rovin BH, Hebert CJ, et al: Management of glomerular proteinuria: A commentary. J Am Soc Nephrol 2003;14: 3217-3232.

112 Sowers JR: Diabetic nephropathy and concomitant hypertension: A review of recent ADA recommendations. Am J Clin Proc 2002;3:27-33.

113 Bolton WK, Cattran DC, Williams ME, et al: Randomized trial of an inhibitor of formation of advanced glycation end products in diabetic nephropathy. Am J Nephrol 2004; 24:32-40.

114 Gambaro G, Kinalska I, Oksa A, et al: Oral sulodexide reduces albuminuria in microalbuminuric and macroalbuminuric type 1 and type 2 diabetic patients: The Di.N.A.S. randomized trial. J Am Soc Nephrol 2002;13: 1615-1625. 
115 Peterson JC, Adler S, Burkart JM, et al: Blood pressure control, proteinuria, and the progression of renal disease. The Modification of Diet in Renal Disease Study. Ann Intern Med 1995;123:754-762.

116 Lea LJ, Hebert L, Lipkowitz M, et al; AASK Study Investigators: Magnitude of proteinuria reduction predicts risk of end-stage renal disease: Results of the AASK trial. In press.

117 Nakao N, Seno H, Kasuga H, et al: Effects of combination treatment with losartan and trandolapril on office and ambulatory blood pressures in non-diabetic renal disease: A COOPERATE-ABP Substudy. Am J Nephrol 2004;24:543-548

-118 Taft JL, Nolan CJ, Yeung SP: Clinical and histological correlations of decline in renal function in diabetic patients with proteinuria. Diabetes 1994;43:1046-1051.

$\checkmark 119$ Mogensen CE: Microalbuminuria, blood pressure and diabetic renal disease: Origin and development of ideas. Diabetologia 1999;42:263-285.

$>120$ Breyer JA: Diabetic nephropathy in insulindependent patients. Am J Kidney Dis 1992; 20:533-554

121 Gall M-A, Rossing P, Skott P, et al: Prevalence of micro- and macroalbuminuria, arterial hypertension, retinopathy and large vessel disease in European type 2 (noninsulin-dependent) diabetic patients. Diabetologia 1991;34:655-661.

-122 Olivarius Nde F, Andreasen AH, Keiding N, et al: Epidemiology of renal involvement in newly-diagnosed middle-aged and elderly diabetic patients: Cross-sectional data from the population-based study 'Diabetes Care in General Practice', Denmark. Diabetologia 1993;36:1007-1016.

$\checkmark 123$ Ravid M, Brosh D, Ravid-Safran D, et al: Main risk factors for nephropathy in type 2 diabetes mellitus are plasma cholesterol levels, mean blood pressure, and hyperglycemia. Arch Intern Med 1998;11:998-1004.

-124 Adamczak M, Zeier M, Dikow R, et al: Kidney and hypertension. Kidney Int Suppl 2002; 80:62-67.

125 Ismail N, Becker B, Strzeclczyk P, et al: Renal disease and hypertension in non-insulin-dependent diabetes mellitus. Kidney Int 1999; 55:1-28.

-126 Hasslacher C, Wolfrum M, Stech G, Wahl P, Ritz E: Diabetic nephropathy in type II diabetes: Effect of metabolic control and blood pressure on its development and course. Dtsch Med Wochenschr 1987;112:14451449.

-127 Mogensen CE: Progression of nephropathy in long-term diabetics with proteinuria and effect of initial hypertensive treatment. Scand J Clin Lab Invest 1976;36:383-388.

128 Parving H-H, Andersen AR, Smidt UM, et al: Early aggressive antihypertensive treatment reduces rate of decline in kidney function in diabetic nephropathy. Lancet 1983;i:1175-1179.

129 Bakris GL, Williams M, Dworkin L, et al: Preserving renal function in adults with hypertension and diabetes: A consensus approach. Am J Kidney Dis 2000;36:646661.
130 Kasiske BL, Kalil RSN, Ma JZ, et al: Effect of antihpertensive therapy on the kidney in patients with diabetes: A meta-regression analysis. Ann Intern Med 1993;118:129_ 138.

131 Bjorck S: Clinical trials in overt diabetic nephropathy; in Mogensen CE (ed): The Kidney and Hypertension in Diabetes Mellitus. Boston, Kluwer Academic Publ., 1998, pp 409-418.

132 Ferder L, Daccordi H, Martello M, et al: Angiotensin converting enzyme inhibitors versus calcium antagonists in the treatment of diabetic hypertensive patients. Hypertension 1992;19(2 suppl):237-242.

133 Hovind P, Rossing P, Tarnow L, et al: Remission and regression in the nephropathy of type 1 diabetes when blood pressure is controlled aggressively. Kidney Int 2001;60: 277-283

134 Hansen HP, Rossing P, Tarnow L, et al: Increased glomerular filtration rate after withdrawal of long-term antihypertensive treatment in diabetic nephropathy. Kidney Int 1995;47:1726-1731.

135 Lewis JB, Berl T, Bain RP, Rohde RD, Lewis EJ: Effect of intensive blood pressure control on the course of type 1 diabetic nephropathy. Am J Kidney Dis 1999;34:809-817.

136 Weidmann P, Boehlen LM, deCourten M: Effects of different antihypertensive drugs on human diabetic proteinuria. Nephrol Dial Transplant 1993;8:582-584.

137 Bjork S: Clinical trials in overt diabetic nephropathy; in Mogensen CE (ed): The Kidney and Hypertension in Diabetes Mellitus. Boston, Kluwer Academic Publ., 1997.

138 Maki DD, Ma JZ, Louis TA, Kasiske BL: Long-term effects of antihypertensive agents on proteinuria and renal function. Arch Intern Med 1995;155:1073-1080.

139 Lasaridis AN, Sarafidis PA: Diabetic nephropathy and antihypertensive treatment: What are the lessons from clinical trials? Am J Hypertens 2003;16:689-697.

140 Bauer JH, Reams GP, Hewett J, et al: A randomized, double-blind, placebo-controlled trial to evaluate the effect of enalapril in patients with clinical diabetic nephropathy. Am J Kidney Dis 1992;20:443-457.

141 Haas M, Leko-Mohr Z, Erler C, et al: Antiproteinuric versus antihypertensive effects of high-dose ACE inhibitor therapy. Am J Kidney Dis 2002;40:458-463.

142 Brenner BM, Zagrobelny J: Clinical renoprotection trials involving angiotensin II-receptor antagonists and angiotensin-convertingenzyme inhibitors. Kidney Int Suppl 2003; 83:S77-S85.

143 Mezzano S, Droguett A, Burgos ME, et al: Renin-antiotensin system activation and interstitial inflammation in human diabetic nephropathy. Kidney Int Suppl 2003;86:S64 S70.

144 Morfelli E, Loon N, Meyer T, et al: Effects of converting-enzyme inhibition on barrier function in diabetic glomerulopathy. Diabetes 1990;39:76-82.
145 Macconi D, Ghilardi M, Bonassi ME, et al: Effect of angiotensin-converting enzyme inhibition on glomerular basement membrane permeability and distribution of zonula occludens-1 in MWF rats. J Am Soc Nephrol 1999; 11:477-489.

146 Kelly DJ, Aaltonen P, Cox AJ, et al: Expression of the slit-diaphragm protein, nephrin, in experimental diabetic nephropathy: Differing effects of anti-proteinuric therapies. Nephrol Dial Transplant 2002;17:13271332.

147 Suzuki Y, Ueno M, Hayashi H, et al: A light microscopic study of glomerulosclerosis in Japanese patients with no insulin-dependent diabetes mellitus. Clin Nephrol 1994;42: 155-162.

148 Taguma Y, Kitamoto Y, Futaki G, et al: The effect of captopril on heavy proteinuria in azotemic diabetics. N Engl J Med 1985;313: 1617-1623.

149 Hamilton RA, Kane MP, Demers J: Angiotensin-converting enzyme inhibitors and type 2 diabetic nephropathy: A meta-analysis. Pharmacotherapy 2003;23:909-915.

150 Lewis EJ: Captopril in type 1 diabetic nephropathy; in Black HR (ed): Clinical Trials in Hypertension. Chicago, Dekker, 2000.

151 Hebert LA, Wilmer WA, Falkenhain ME, et al: Renoprotection: One or many therapies? Kidney Int 2001;59:1211-1226.

152 Ravid M, Lang R, Rachmani, et al: Longterm renoprotective effect of angiotensinconverting enzyme inhibition in non-insulindependent diabetes mellitus. Arch Intern Med 1996;156:286-289.

153 Bakris GL, Williams M, Dworkin L, et al: Preserving renal function in adults with hypertension and diabetes: A consensus approach. Am J Kidney Dis 2000;36:646661.

154 Parving H-H: Angiotensin II receptor blockade in the prevention of diabetic nephropathy. Am J Clin Proc 2002; 3:21-26.

155 Ruilope LM, Segura J: Losartan and other angiotensin II antagonists for nephropathy in type 2 diabetes mellitus: A review of the clinical trial evidence. Clin Ther 2003;25:30443064.

156 Hilgers KF, Mann JFE: ACE inhibitors versus AT1 receptor antagonists in patients with chronic renal disease. J Am Soc Nephrol 2000;13:1100-1108.

157 Andersen S, Blouch K, Bialek J, et al: Glomerular permselectivity in early stages of overt diabetic nephropathy. Kidney Int 2000;58:2129-2137.

158 Andersen S, Jacobsen P, Tarnow L, et al: Time course of the antiproteinuric and antihypertensive effect of losartan in diabetic nephropathy. Nephrol Dial Transplant 2003; 18:293-297.

159 Praga M, Morales E: Renal damage associated with proteinuria. Kidney Int 2002;62: S42-S46.

160 Nakao N, Yoshimura A, Morita H, et al: Combination treatment of angiotensin-II receptor blocker and angiotensin-convertingenzyme in nondiabetic renal disease (COOPERATE): A randomized control trial. Lancet 2003;361:117-124. 
161 Ots M, Mackenzie HS, Troy JL, Rennke HG, Brenner BM: Effects of combination therapy with enalapril and losartan on the rate of progression of renal injury in rats with 5/6 renal mass ablation. J Am Soc Nephrol 1998;9: 224-230.

162 Campbell RC, Ruggenenti P, Remuzzi G: Halting the progression of chronic nephropathy. J Am Soc Nephrol 2002;13:S190-195.

163 Komine N, Khang S, Wead LM, et al: Effect of combining an ACE inhibitor and an angiotensin II receptor blocker on plasma and kidney tissue angiotensin II levels. Am J Kidney Dis 2002;39:159-164.

164 Thurman JM, Schrier RW: Comparative effects of angiotensin-converting enzyme inhibitors and angiotensin receptor blockers on blood pressure and kidney. Am J Med 2003; 114:588-598.

165 Lewis EJ, Lewis JB: ACE inhibitors versus angiotensin receptor blockers in diabetic nephropathy: Is there a winner? J Am Soc Nephrol 2004; 15:1358-1360.

166 Gerstein HC, Yusuf S, Mann JFE, et al: Effects of ramipril on cardiovascular and microvascular outcomes in people with diabetic mellitus: Results of the HOPE study and MICRO-HOPE substudy. Heart Outcomes Prevention Evaluation Study Investigators. Lancet 2000;355:253-259.

167 Lindholm LH, Ibsen H, Dahlof B, et al; LIFE Study Group: Cardiovascular morbidity and mortality in patients with diabetes in the losartan intervention for endpoint reduction in hypertension study (LIFE): A randomized trial against atenolol. Lancet 2002;359: 1004-1010.

168 Sica D: ACE inhibitor intolerance and lessons learned from the candesartan in heart failure: Assessment of reduction in mortality and morbidity (CHARM) trials. Congest Heart Fail 2004;10:160-164.
169 Pfeffer MA, Swedberg K, Granger CB, et al: Effects of candesartan on mortality and morbidity in patients with chronic heart failure The CHARM-Overall program. Lancet 2003; 362:759-766.

170 Pfeffer MA, McMurray JJV, Velazquez EJ, et al; Valsartan in Acute Myocardial Infarction Trial Investigators: Valsartan, captopril, or both in myocardial infarction complicated by heart failure, left ventricular dysfunction, or both. N Engl J Med 2003;349:18931906.

171 McMurray JJV, Ostergren J, Swedberg K, et al; CHARM Investigators and Committees: Effects of candesartan in patients with chronic heart failure and reduced left-ventricular systolic function taking angiotensin-converting-enzyme-inhibitors: The CHARM-Added trial. Lancet 2003;362:767-771.

172 Mogensen CE, Neldam S, Tikkanen I, et al: Randomized controlled trial of dual blockade of rennin-angiotensin system in patients with hypertension, macroalbuminuria, and non-insulin dependent diabetes: The candesartan and lisinopril macroalbuminuria (CALM) study. BMJ 2000;321:1440-1444.

173 Jacobson P, Andersen S, Jensen BR, et al: Additive effect of ACE inhibition and angiotensin II receptor blockade in type I diabetic patients with diabetic nephropathy. J Am Soc Nephrol 2003;14:992-999.

174 Russo D, Pisani A, Balletta MM, et al: Additive antiproteinuric effect of converting enzyme inhibitor and losartan in normotensive patients with IgA nephropathy. Am J Kidney Dis 1999;33:851-856.

175 Rosner MH, Okusa MD: Combination therapy with angiotensin-converting enzyme inhibitors and angiotensin receptor antagonists in the treatment of patients with type 2 diabetes mellitus. Arch Intern Med 2003;163 1025-1029.

176 Chobanian AV, Bakris GL, Black HR, et al: The seventh report of the joint national committee on prevention, detection, and treatment of high blood pressure: The JNC 7 report. JAMA 2003;289:2560-2571.
177 Singer GM, Izhar M, Black HR: Guidelines for hypertension: Are quality-assurance measures on target? Hypertension 2004;43:198202.

178 Boero R, Rollino C, Massara C, et al: The verapamil versus amlodipine in nondiabetic nephropathies treated with trandolapril (VVANNTT) study. Am J Kidney Dis 2003; 42:67-75.

179 Bakris GL, Weir MR, Secic M, et al: Differential effects of calcium antagonist subclasses on markers of nephropathy progression. Kidney Int 2004;65:1991-2002.

180 Smith AC, Toto R, Bakris GL: Differential effects of calcium channel blockers on size selectivity of proteinuria in diabetic glomerulopathy. Kidney Int 1998;54:889-896.

181 Bakris GL, Weir MR, DeQuattro, et al: Effects of an ACE inhibitor/calcium antagonist combination on proteinuria in diabetic nephropathy. Kidney Int 1998;54:1283-1289.

182 Greene T, Lau J, Levey AS: Interpretation of clinical studies of renal disease; in Neilson EG, Couser WG (eds): Immunological Renal Diseases. Philadelphia, Lippincott-Raven, 1997, pp 887-911.

183 Bolton WK: The nature of clinical trials in nephrology. Kidney Int 1992;42:10611069.

184 D'Amico G: Assessment of endpoints in the study of progressive renal disease: Summary and concluding remarks. Kidney Int 1994; 45(S45):S132-133.

185 Bakris GL, Whelton P, Weir M, et al: The future of clinical trials in chronic renal disease: Outcome of an NIH/FDA/Physician Specialist Conference. Evaluation of Clinical Trial Endpoints in Chronic Renal Disease Study Group. J Clin Pharmacol 2000;40: 815-825.

186 Striker GE, Klahr S: Clinical trials in progression of chronic renal failure. Adv Intern Med 1997; $42: 555-595$. 